\title{
Surgery today: smile clears the tide
}

\author{
F. M. Riegler
}

Published online: 2 December 2014

(C) Springer-Verlag Wien 2014

\section{Dear reader,}

Reading those lines you are allowed to bypass your boss, become important and download yourself and come into existence. Welcome. Everybody has a boss. Even a dean, minister, king, pope, head of an institution and president has to report his/her data to a boss (woman, man). Nothing appears as absence at the cost of perception. The others are the cowards, not you. The others are the hypocrites, not you. The others are full of hunger, greed, envy and hate, not you. The others want to have power and influence, not you. The others want to be important and present in the public, not you. The others misuse power networks for their benefit, not you. One word only harbors the power and clarity to cover and express the entire spectrum of human behaviour. The others are the egoists, not you. The others hide behind the materialistic glitter of their possessions, not you. The others invent excuses and alibi, not you. The others do not take the responsibility for their actions, not you. The others pretend to be perfect, excellent, invincible and durable, not you. The others claim guidelines, justice and ethics, not you. The others hide behind political, religious, atheistic clubs, parties and societies to justify their action and dilute their responsibility, not you. The others neglect the essence, not you. While you are performing surgery and medical care with honest love in your eyes, the others are, not you.

Interwoven within the minimally invasive but highly effective spectrum shade network of pluripotent powers, deduced desires, humbled hopes and wave-giving wills, resides the itinerant individual to follow the particular purpose of existence: to be. During the common trunk

F. M. Riegler ( $\square)$

Reflux Medical,

Mariannengasse 10/9,

1090 Vienna, Austria

e-mail: martin.riegler@refluxmedical.com education, the common energy drink drunk face book posted pill beaten surgeon learns to e-mail about a misty in-roots-miracle. And the magic flute tunes along the fortune benefit that it does not show up. The short message system knows: it simply is.

Continuous freedom does not exist. Continuous independence from social, political, economic, physical, psychological, emotional, nutritional and behavioural needs does not exist. Continuous freedom from mental and hormonal drives does not exist. Nothing is permanent. Nothing is permanent. Permanent tolerance, respect for others does not exist. Permanent freedom from hunger, greed, envy and hate does not exist. Continuous flow of lack-free tune of mood does not spell out. All is transient. $A l l$ is transient. Permanent open-minded reasoning does not exist. Existence of the human being fosters the up and downs, the pros and cons, the shine and dark sides of the tide. Continuous economic stability does not exist. At present an increasing number of people feel some sort of insecurity regarding the future economic, social and educational developments in Europe and North America $(p<0.0001)$. Some even fear the upcoming of a Third World War. Along the surface glitters the mood. Waves harbor forces. Essentially revolutions turn, but do not bring it to a change, it always remains to be the same tide (Fig. 1a-c). There only exists one tide, and it is beyond different manifestations (Fig. 1d).

The tide itself is the representation of the cosmos and shines as mingling transient glitter above the surface of the waters of our dreams, hopes and desires. You are not always allowed to express what you think. Even a leader hides what he thinks about his employees. As a rule for baseball academics: outline fuses, outfield kills, fill the base, everybody waits for the home run. Innings are far from being perfect. Fate replaces the lack limos that opens and unhides beyond knowledge (limos; Greek $\lambda \iota \mu$ ó $\varsigma=$ lack, hunger, deficit). Oncologic surgery teaches: there are a lot of facts that we are allowed to 
Fig. 1 The image mirrors the manifestation of the transient pulse of the highly powerful tide, which disrupts a continuity of materialistic perception within the setting of a public park benchmark activity (a-c) and the open sea (d), as outlined in the text. Roots up (c) indicates, that any revolution is mistaken for a change, but essentially any revolution lacks novelty, actuality and relevance since it simply turns up to manifest as another aspect of a spectrum under which breathes the same well-hidden single idea: the essence of the tide reveals being (d). Image obtained in the Vienna Central Park following a powerful, turbulent wind storm $(\mathbf{a}-\mathbf{c})$, and in stormy Siracusa, Sicily (d), using iPhone technology
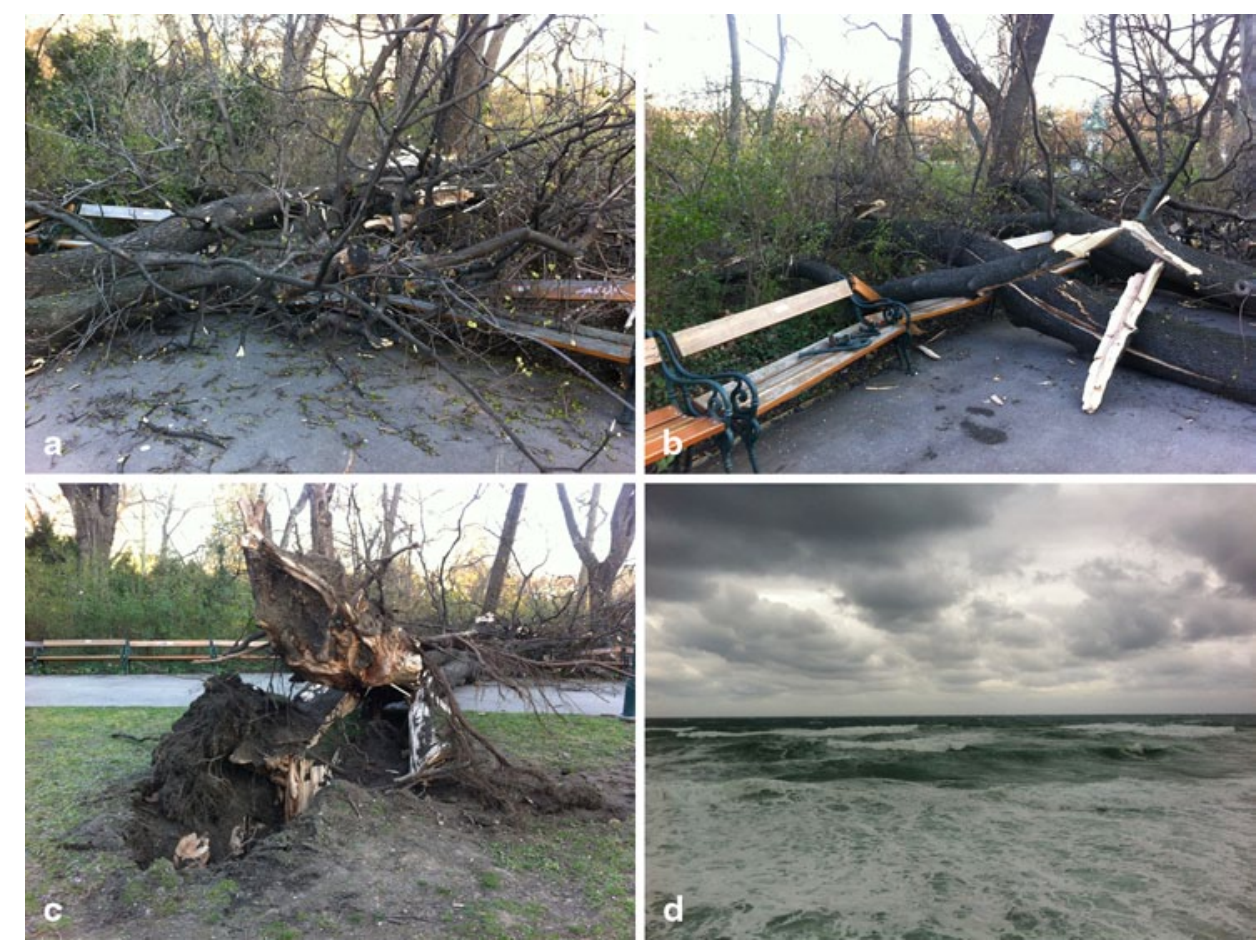

know $(p<0.001)$. Palliation serves to keep in mind: the majority of questions does not foster an answer. Cancer therapy offers a great market, the economic burden is taken by the social and by the private insurance system. Statistics take it all. Sometimes analysis of the data are to be tailored according to the needs and perspectives of those who protocol the game (from share to care). As a consequence, the cooperation of the medical industry and the physicians produce chemotherapy boiled boilers who end up as cut into little pieces insects within in the well smell section theatre of the honourable pathological institute (wake up and live up). Death is the endpoint of the study. Death is the endpoint of the study. Thus the $p$-values continue to transiently feed the ugly and feculent tides for the benefit of the shareholders of the pharmaceutical and medical industry, from time to time, but not always and never as a continuous stream of power. However, this only mirrors one part of the game. The other beautiful part of the game grows the colourful flowers in the meaningful greedy grass to improve survival \pm life quality, productivity and well-being $(p<0.02)$. Charity keeps up with the other extremes of the system and aims to compensate ethical imbalance.

No opinion is perfect. No opinion is permanent, no consideration is continuous, the only continuous and permanent essence teaches: change matters, word speaks, reasoning is. In between this action the materialistic world keeps us from unhiding the essence of the mainly forgotten: birth and death are the only innings not to be remembered. The only continuity is based on the fact, that possibility orders as a transient tide. Remains to be questioned the relevance of the limos lack for a time tailored approach (Table 1).

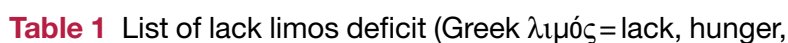
deficit): causes for imbalance and disease

\begin{tabular}{|c|c|c|}
\hline Lack/limos types & Manifestation & Therapy \\
\hline $\begin{array}{l}\text { Lack of respect and } \\
\text { attention }\end{array}$ & $\begin{array}{l}\text { Unstable personality, } \\
\text { pride }\end{array}$ & $\begin{array}{l}\text { Outbalanced attention, } \\
\text { mediation }\end{array}$ \\
\hline Lack of energy & $\begin{array}{l}\text { Mental \& physical } \\
\text { weakness }\end{array}$ & $\begin{array}{l}\text { Mental coaching, metabolic } \\
\text { balance, exercise, workout }\end{array}$ \\
\hline Lack of education & $\begin{array}{l}\text { Danger to be } \\
\text { manipulated and } \\
\text { misused }\end{array}$ & $\begin{array}{l}\text { Teaching, learning, educa- } \\
\text { tion }\end{array}$ \\
\hline $\begin{array}{l}\text { Lack of love and self- } \\
\text { esteem }\end{array}$ & Frustration, isolation & Love and care \\
\hline Lack of responsibility & Coward, hypocrite & Not known \\
\hline \multicolumn{3}{|c|}{ 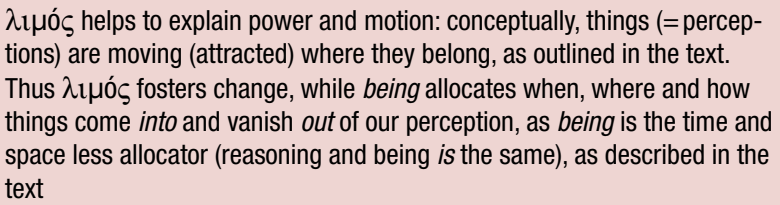 } \\
\hline
\end{tabular}

Conceptually, things move to the place they belong. Thus, things move on to compensate and outbalance what they lack at a given place, i.e. stability and balance of space, time and yet undefined stages of energy. Space considers time to pass, time reveals space to open and close. Welcome to the inner circle. Imbalance is the driving force for a change. Who decides if things have to move? The allocator. Who decides where, when and how things appear, come into existence and vanish out of perception? The allocator. Who decides on time, space and energies? The allocator. How does the allocator express? The allocator expresses with speech, words, language, sounds, noise, breath and images. As such speech, words, language, sounds, breathes and thoughts 
are representations and manifestations of the allocator? Yes. Who decides on the number of manifestations? The allocator. Who decides on survival outcome calculated for oncologic studies? The allocator. Who decides on the duration of a given economic, political, social, mental and environmental system? The allocator. Who ends the reign of a king, dean, pope, minister, head, president, dictator, leader? The allocator. Who starts and ends bliss, happiness, sorrow and grief? The allocator. Who commences and finishes hate, envy, greed and fate? The allocator. Who creates gods, saints, devils and ghosts? The allocator. Who offers spirit, body and soul? The allocator. Who offers day, night and twilight? The allocator. Who offers sleep, dream and life? The allocator. Who expresses as ourselves? The allocator. Who is the allocator? Being. Reasoning and being is the same. Beyond that orchestrates the fundamental quiet tide of your individual state of mood. This may reveal the very essence of the tune depicted in the editorial of Thomas Hölzenbein within the present issue of European Surgery.

Third world ninety six degrees in the shade, 60 or $45 \mathrm{~h}$ ordered work at the Crab Cancer Cuboid Wonderland Medical University, packed within a mega-sized XXXlarge concrete heavy metal glass mixture multilevel CUBOID tower. At present, lack limos of income increases the economic burden of the generations of surgeons, nursing personal, technicians and patients. Life quality and productivity significantly decreases $(p<0.002)$. Leaders take it all, what remains is the fall. As outlined in the present issue of European Surgery, vascular surgery teaches: outbalance the flow using surgical/interventional and non-surgical/interventional means as long as you can, otherwise the lack of limos will bring you out of your current form of existence and vanish within the spectrum of perception, data and statistical calculation $(p<0.05)$. Look out for another gate of fate (tune of mood not investigated).

Who sees the facts, feels that the twilight is coming up to nourish the tide to bring it all to the fall. Necessity feeds the needs. Stress causes imbalance (Fig. 2). Conceptually therapy aims to reduce, eliminate, outbalance stress towards balance (Table 1) (Fig. 3). Environmental pollution makes man appear as an infectious disease of the planet earth (mundoitis chronica, acuta, non-idiopathica). Will earth open the mouth and swallow mankind? Remains to be questioned the subsequent taste of reflux, for both man and planet earth.

Man is, consequences are. Therefore, we should open our minds for askesis, to focus on the essential drives to keep up with the individual economic, mental and physical prerequisites. Demands nourish hunger. This helps to protect ourselves to face the upcoming hard core of the tide. Currently academic and social politics open the gates for the tide to come. As well presented by Thomas Hölzenbein in this issue of European Surgery, prophets love rains, do not get wet and do not mind, if we listen to their songs or not. The tide does not care what we think about it. We are the ones who are getting wet. The sun does not mind, what we think about it, it just does what it

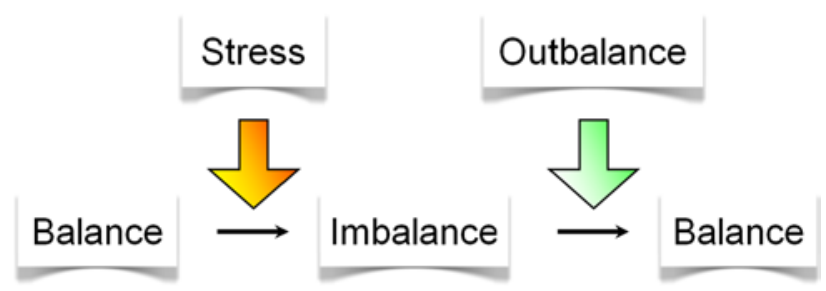

Fig. 2 Conceptually, disease is the consequence of imbalance, which itself results from stress. Effective therapy aims to eliminate stress to outbalance health and well-being, as outlined in the text

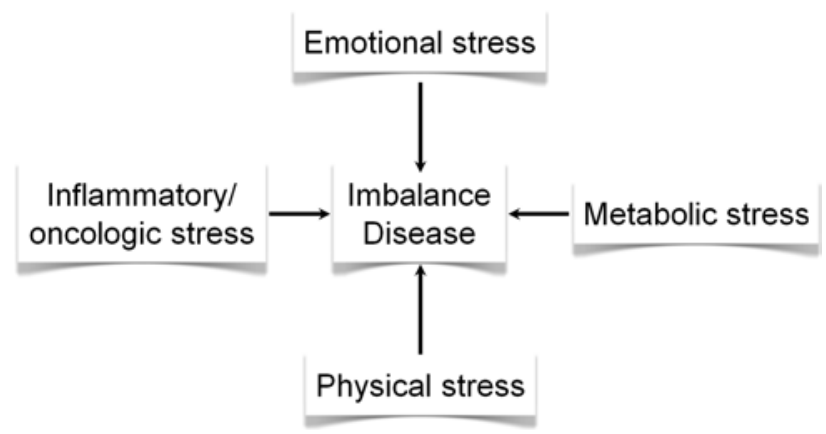

Fig. 3 The image cartoons different types of imbalance-inducing forms of stress. Conceptually stress fosters imbalance and disease. Effective medical and/or surgical and/or interventional therapy aims to eliminate, compensate and outbalance stress to achieve health and well-being, as outlined in the text

aims for, it simply is to shine. Now we are at turn to catch the message right now: disease aims to call for action (Table 1). Who of you likes to be a sun, who of you wants to be a moon, who of you withstands the life and perception giving firing heat of being...a star? The stone age did not end because of the lack limos of stones.

Taken together, let us open up our minds to keep up with the fundamental and highly powerful tide, which is definitely going to come. Let us tailor and outbalance our life, let us reduce our needs, wants and drives in favour for the essential. Let us open our eyes for the message within and in between the lines of the current issue of European Surgery. It lists more than facts and excellence, what Thomas Hölzenbein is going to cut out of the body of wisdom, knowledge, reasoning and thought. Try to level out, clear, settle and calm the tide with a smile. Smell the quiet taste of enlightenment, enjoy as summer warms up the south half of our diamond planet. Stop isolation and express brilliance, as....

$$
\begin{gathered}
\text { your } \\
\text { perception } \\
\text { is reasoning is } \\
\text { interpretation of your } \\
\text { stream of mood } \\
\text { is being is } \\
\text { you. }
\end{gathered}
$$


Gratitude, humility and love prosper to catch a sounding smile of freedom, far off the busy surface fire rubbling bubbling and humbling a hatch of heroes. As they foliate, do they hide the once upon a time security shelter theme of the branch, stem, roots of the tree, the fabulous miracle of soil, water, well, air, clouds, winds and the sea? As those drops are put into oceans they may be allowed to return to the rainbow and continue the colourful bridge of shine for YOU. Outbalance yourself and be YOU.

\section{Acknowledgements}

The author thanks Prof. Dr. Thomas Hölzenbein for his intellectual and personal contributions and his deep friendship. In addition this is to express thanks and grati- tude to the Viennese writer and twisted essayist Franz Schuh, who, with his contributions, perfectly catches and mirrors the tune of mood of our present time and profoundly stimulates and provokes the reasoning of the author. Finally the Editorial is dedicated to the young surgeons in the EU, who are at turn to actively design the future of their profession. May the Editorial be a stimulator for these important achievements.

\section{Conflict of interest}

The author declares that there exists no conflict of interest. 